\title{
Diálogos Entre a Academia e a Cenografia: A contribuição do CENOTEC UFRN para este debate na PQ Talks da Quadrienal de Praga 2019
}

\author{
José Sávio Oliveira de Araújo \\ Universidade Federal do Rio Grande do Norte - UFRN, Natal/RN, Brasil \\ E-mail: savarau@gmail.com
}

\section{Resumo}

O presente ensaio apresenta uma reflexão acerca da participação brasileira em um importante painel da Quadrienal de Praga 2019, o PQ Talks intitulado: "What has the academy done to or for scenography?" (O que a academia tem feito para ou pela Cenografia?), durante a Quadrienal de Praga 2019, em Praga, República Tcheca. Participaram deste painel pesquisadores da área de Cenografia de sete países, de diferentes continentes, permitindo observar uma significativa amostragem de questões que pautam a contribuição do espaço acadêmico na atividade cenográfica mundial em diferentes âmbitos e recortes. O foco aqui abordado se concentra no impacto gerado pela contribuição brasileira, neste painel, que apresentou um trabalho produzido por meio do PIBID TEATRO CAPES e desenvolvido do CENOTEC - Laboratório de Estudos Cenográficos e Tecnologias da Cena - DEART/UFRN em parceria com escolas públicas da rede municipal de ensino do município de Natal, RN, Brasil. Uma experiência inédita de introdução do Ensino de Cenografia no Ensino Fundamental, em escolas públicas, que expressou e exemplificou algumas inquietações apontadas pelos painelistas, resultando numa importante contribuição brasileira, tanto pelo seu ineditismo como pela demonstração de sua natureza interdisciplinar e articulações entre formação de professores de teatro, pesquisa universitária e inserção social da produção acadêmica.

\section{Palavras-chave}

Quadrienal de Praga 2019. Diálogos acadêmicos. Ensino de Cenografia.
This essay presents a reflection on Brazilian participation in an important panel of the Prague Quadrennial 2019, PQ Talks entitled: "What has the academy done to or for scenography?", during the Prague Quadrennial 2019, in Prague, Czech Republic. This panel was attended by scenography researchers from seven countries, from different continents, allowing us to observe a significant sample of issues that guide the contribution of the academic space in the world scenographic activity in different areas and cuttings. The focus here focuses on the impact generated by the Brazilian contribution, in this panel, which presented a work produced through PIBID TEATRO UFRN and developed by CENOTEC - Laboratory of Scenographic Studies and Technologies of the Scene - DEART / UFRN in partnership with public schools of the municipal school system of Natal, RN, Brazil. An unprecedented experience of introducing Scenography Teaching in Elementary School, in public schools, which expressed and exemplified some concerns pointed out by the panelists, resulting in an important Brazilian contribution, both for its unprecedented nature and for the demonstration of its interdisciplinary nature and articulations between theater teacher education, university research and social insertion of academic production.

Keywords

Prague Quadrennial 2019. Academic Dialogues. Scenography Teaching. 


\section{Introdução}

A Quadrienal de Praga do Espaço e Design da Performance ${ }^{1}$ é considerada como um dos eventos mais importantes da Cenografia ${ }^{2}$ mundial. Dentre os aspectos que contribuem para a relevância deste evento, evidencia-se a diversidade dos formatos das atividades que compõem sua programação, como destaca a organização da edição 2019, em seus releases para a imprensa:

\begin{abstract}
"AQuadrienal de Praga de Design e Espaço de Performance, que acontece de 6 a 16 de junho de 2019 no Prague Exhibition Grounds, publicou seu programa completo. Ao longo de 11 dias, o evento de teatro do ano oferece exposições de 79 países, mais de 800 artistas de todo o mundo e mais de 600 apresentações, oficinas e palestras. (...) a série de palestras $P Q$ Talks on-line e as mais de 50 apresentações exibidas como parte do $P Q$ Studio: Festival organizado pela DAMU"3. (tradução do autor).
\end{abstract}

10 termo performance é aqui compreendido em seu sentido mais amplo nas artes cênicas, abrangendo diversas linguagens artísticas, inclusive a performance arte.

2 Neste texto, o termo Cenografia é utilizado no lugar de Performance Design, que é um angliscismo e ainda não goza de uma aceitação hegemônica entre os paises de língua portuguesa e hispânica. Pode-se dizer que um dos aspectos que caracterizam o estado da arte desta área de conhecimento reside exatamente num debate, ainda em curso, visível em diversos seminários, congressos e publicações da área, acerca da terminologia que melhor caracterizaria a Cenografia contemporânea, em decorrência de conceitos, fundamentos e especialidades produzidos na atualidade, em contraposição às concepções tradicionais do termo Cenografia.

3 The Prague Quadrennial of Performance Design and Space, which takes place from 6 to 16 June 2019 at the Prague Exhibition Grounds, has published its complete program. Over the course of 11 days, the theater event of the year offers expositions from 79 countries, more than 800 artists from around the world, and over 600 performances, workshops, and lectures. (...) the $P Q$ Talks lecture series online and for the more than 50 performances being shown as part of $P Q$ Studio: Festival organized by DAMU(...). (PRAGUE QUADRENNIAL, 2019. Documento eletrônico).
Dentre essas atividades destaco a $P Q$ Talks, um conjunto de palestras organizadas em formato de mesa redonda/painel, com duração de uma hora e quarenta e cinco minutos, com a participação de convidados de diversos países. A fala de cada participante, estabelecida em oito minutos, compôem, assim, um rico painel sobre o tema abordado em cada sessão, que é ampliado pelas contribuições da audiência nos debates, ao final das falas dos convidados. Esta atividade está assim descrita no press release da PQ 2019 quando do lançamento da programação oficial:

\begin{abstract}
"A série de discussões e palestras do $P Q$ Talks analisa as tendências contemporâneas da cenografia e envolve uma reflexão crítica sobre a colaboração artística no teatro, incluindo técnicas, processos e fontes de inovação. Os curadores Pavel Drábek e Barbora Príhodová convidaram não apenas estrelas de vários campos, mas também artistas que apenas recentemente começaram suas carreiras"4. (tradução do autor).
\end{abstract}

O fato da atividade envolver tanto nomes já consolidados noâmbito da pesquisa acadêmica quanto jovens pesquisadores em inicio de carreira, fortalece o aspecto da diversidade de pontos de vista acerca do tema do painel, possibilitando confrontar visões já estabelecidas com abordagens ainda em construção.

\section{A PQ Talk "What has the academy done to or for scenography?"}

Esta atividade foi proposta para a PQ 2019 por Joslin McKinney, professora e pesquisadora da University of Leeds (Reino Unido), que convidou para compor o painel os seguintes pesquisadores(as)/professores(as):

\footnotetext{
4 The PQ Talks discussion and lecture series looksat contemporary trends in scenography and engages in a critical reflection on artistic collaboration in theater, including techniques, processes, and sources of innovation. Curators Pavel Drábek and Barbora Príhodová have invited not only stars from the various fields but also artists who only recently began their careers. (PRAGUE QUADRENNIAL,2019. Documento eletrônico).
} 
Arnold Aronson ${ }^{5}$ (Columbia University USA); Dorita Hannah (Scholar/Design - Finlândia/ Nova Zelândia); Mia David (University of Novi Sadi - Sérvia); Thea Brejzek (University of Technology, Sidney - Australia); Sávio Araújo (UFRN - Brasil); Scott Palmer (University of Leeds - Reino Unido), Liu Xinling (Central Academy of Drama, Beijing - China). O painel aconteceu no dia 11 de junho de 2019, no Pavilhão Krizik, do Palácio Industrial Vystaviste, Praga, República Tcheca, das 16:15 às 18:00. Joslin McKinney, organizadora desta PQ Talk, contribuiu e facilitou a compreensão acerca do tema a ser debatido, enviando, em carta convite aos painelistas, a seguinte contextualização:

"A $P Q$ tem um compromisso de longa data com a próxima geração de cenógrafos e performance designers, recebendo estudantes de todo o mundo como uma parte vital da comunidade cenográfica. Consequentemente, o papel desempenhado por instituições acadêmicas e professores no desenvolvimento da $P Q$ e seus eventos associados tem sido significativo. Ao longo dos anos, essa contribuição mudou de um foco em um modelo de aprendizado para um modo mais ativo e dialógico de explorar maneiras de fazer e apresentar Cenografia. Recentemente, as exposições de estudantes adotaram questões fundamentais sobre a natureza da performance design contemporânea e as maneiras pelas quais ela pode se envolver e se conectar com o público. Isso é parcialmente uma resposta ao desenvolvimento da performance design profissional, mas também foi influenciado por pesquisas acadêmicas que se refletem de vários modos nos currículos e que estabeleceram a posição da Cenografia como um campo de pesquisa acadêmica. O papel da academia no desenvolvimento

5 Infelizmente, o Prof. Arnold Aronson não pôde participar do painel, pois teve que cancelar sua ida à $P Q 2019$, devido a contratempos de última hora. da compreensão da cenografia também se reflete no aumento de publicações acadêmicas sobre Cenografia. Com esses desenvolvimentos, surgem oportunidades para um reconhecimento mais amplo do que a cenografia pode fazer, mas também há tensões; as agendas das instituições de ensino superior não estão necessariamente alinhadas com as necessidades criativas e comerciais da prática profissional ou da 'indústria'"'6. (tradução do autor).

Desse modo, em suas falas, os convidados debateram as seguintes questões: como os desenvolvimentos no ensino superior afetaram a relação entre academia e prática profissional? Quais são os benefícios e os desafios desses relacionamentos? Quais são os caminhos a seguir para as relações produtivas entre academia e profissão?

A diversidade dos lugares de fala dos participantes deste painel, alguns oriundos de universidades tradicionais e outros oriundos de países de economias periféricas e cujas universidades ainda lutam para se consolidar, imprimiu ao debate uma riqueza singular, haja vista que, em eventos de participação mais localizada, é difícil se obter uma perspectiva global dos aspectos que caracterizam a área de conhecimento da cenografia, suas

$6 P Q$ has a longstanding commitment to the next generation of scenographers and performance designers, welcoming students from all over the world as a vital part of the scenographic community. Consequently, the part played by academic institutions and teachers in the development of $P Q$ and its associated events has been significant. Over the years, this contribution has shifted from a focus on an apprenticeship model of learning towards a more active and dialogic mode of exploring ways to do and present scenography. Student exhibits recently have embraced fundamental questions about the nature of contemporary performance design and the ways it might engage and connect with audiences. This is partly a response to developments in professional performance design, but it has also been influenced by academic research that is variously reflected in curricula and which has established the standing of scenography as a scholarly field of enquiry. The role of the academy in the developing understanding of scenography is also reflected in increase of scholarly publications about scenography. With these developments come opportunities for wider recognition of what scenography can do, but there are also tensions; the agendas of higher education institutions are not necessarily in line with the creative and commercial needs of professional practice or of 'industry'. (MCKINNEY, 2019). 
epistemes e tensões decorrentes das diversas formas de organização e produção de conhecimento nesse campo das artes cênicas. No entanto, também foi possível observar que, apesar das diferenças de contextos, algumas tensões e preocupações se tornam recorrentes no campo da cenografia e suas relações com o ambiente acadêmico.

Dentre as abordagens apresentadas pelos painelistas destacaram-se as tensões e contrapontos gerados pela relação entre a formação acadêmica institucional em Cenografia e as necessidades criativas e comerciais da prática profissional. Nesse contraponto, percebeu-se claramente uma tensão entre os rigores exigidos pela produção do conhecimento de natureza acadêmica e a necessidade de uma maior liberdade transgressora, mais identificada com a produção artística produzida fora do âmbito acadêmico.

Outras falas dos painelistas destacaram os desafios enfrentados pelos professores em seus espaços de formação acadêmica, tanto no que diz respeito ao repertório multicultural dos estudantes destes cursos, quanto aos hábitos decorrentes de sociedades globalizadas e informatizadas e as demandas políticas que atravessam e marcam as produções destes estudantes.

Outras falas apontaram a tensão decorrente da necessidade dos processos criativos em cenografia se adequarem aos parâmetros teóricometodológicos do ambiente acadêmico, produzindo inquietações no sentido de "empurrar" as fronteiras das compartimentalizações acadêmicas, produzindo novos e profícuos diálogos epistêmicos.

Essa tensão pode significar um leitmotif (motivo condutor) na dialética da relação "academia X ambiente profissional", dinamizando as ideias e conceitos de ambos os lados numa perspectiva dialógica interessante.

As ideias consolidadas num ambiente acadêmico contribuem para a formação de uma massa crítica acerca dos conceitos, fundamentos e princípios que organizam epistemologicamente a cenografia e suas estruturas de conhecimento, possibilitando organizações curriculares e sistematizações didáticas e pedagógicas desses saberes e práticas.

Já a produção oriunda do ambiente profissional, no exercício do trabalho cenográfico, em coletivos teatrais fora do mainstreaming, empurra e dilui as fronteiras dos conceitos consolidados nos ambientes acadêmicos, trazendo novas ideias e concepções que podem renovar o repertório das estruturas desse conhecimento organizado na academia.
Desse modo, no debate transcorrido nesta PQ Talk, foi evidenciando-se a importância dos diálogos multiculturais, multidisciplinares e interdisciplinares para o desenvolvimento da cenografia, dentro e fora da academia.

Esse debate adquiriu contornos relevantes, haja vista que, nos diálogos entre a academia e o ambiente profissional em cenografia já se fazem notar mútuas influências nas formas de organização da pesquisa acadêmica e do trabalho cenográfico, criando novas especialidades nas Artes Cênicas e novos campos de investigação acerca do papel da Cenografia nos estudos sobre a cena. As influências mútuas entre ambos interlocutores do diálogo Academia/Cenografia favorecem o surgimento de novas abordagens, valiosas para a ampliação da Cenografia e suas rupturas epistemológicas (BACHELARD, 1983), bem como para a superação das fronteiras que delimitam esse campo e que interpenetram outras regiões epistemológicas contidas no universo das Artes Cênicas. A noção de obstáculo epistemológico foi formulada por Gaston Bachelard, em 1938, em seus estudos acerca da epistemologia das ciências e consiste numa tensão gerada pelos conceitos e formulações oriundos de diferentes áreas de conhecimento. O fato de cada área abordar seus problemas e construir conhecimentos a partir de seus pontos de vista, estruturas de conhecimento, técnicas e metodologias próprias, resulta em diferentes formas de conhecer e organizar esse conhecimento.

Quando essa tensão, prejudica o avanço de novas concepções e dificuta a afirmação de novas ideias, então, se faz necessária uma superação desses obstáculos. A esse fenômeno epistemológico Bachelard chamou de ruptura epistemológica.

Por exemplo, no campo da Performance Design, a noção de que o termo "cenografia" se restringe exclusivamente à "cenário", pode ser entendido como um obstáculo epistemológico, pois compreende-se cada vez mais que a cenografia é resultante de um conjunto de fatores como iluminação, figurino, maquiagem, sonoplastia e, também, cenário. A não compreensão de que a Cenografia é resultante de uma relação dialética entre esses fatores pode acarretar em um obstáculo epistemológico, pois esse conjunto incide diretamente naquilo que resultará no espaço da performance e não depende somente de um único fator. Um dos aspectos mais relevantes, evidenciados pelo debate nesta $P Q$ Talk, foi a 
tensão existente entre as formas de organização da produção de conhecimento nos espaços acadêmicos e as estratégias de produção de conhecimento gestada pelos espaços artísticos fora do muros da academia. Tensão esta que se revela cada vez mais provocativa e benéfica para todos.

Ao participar deste debate, a UFRN buscou demonstrar, por meio de sua produção em ensino de cenografia, no âmbito do CENOTEC, que o conhecimento cenográfico produzido pelos círculos de investigação, dentro e fora da academia, pode, também, ser acessível aos sujeitos na educação básica, pois constituem um campo multidisciplinar extraordinário para o diálogo entre diferentes área do saber.

\section{- A contribuição do CENOTEC UFRN para}

\section{este debate na PQ 2019}

Foi um longo percurso até a $P Q$ Talk da $P Q$ 2019. Desde 2007 venho me aproximando da Quadrienal de Praga e do trabalho de articulação dos brasileiros que dela participam.

A Quadrienal de Praga tem sido uma fonte de inspiração e um norte acerca dos caminhos que vêm sendo trilhados pela cenografia em diferentes partes do planeta.

Em 2011, o CENOTEC se mobilizou e estimulou os estudantes a inscreverem suas produções, o que resultou na primeira participação da UFRN neste evento internacional, por meio do envio dos trabalhos, dos graduandos Felipe Cabral e André Bezerra, para a Mostra dos Estudantes da PQ 20117.

Em 2015, pude participar da Quadrienal pela primeira vez, mas não apresentamos trabalho. Nessa ocasião, pude conferir in loco toda riqueza e diversidade que permeia uma Quadrienal de Praga. Ao longo das muitas visitações que realizei à Mostra dos Países e Mostra dos Estudantes, bem como ao participar de círculos de debates, em particular sobre ensino de iluminação cênica, pude compreender melhor o formato e o perfil dos participantes daquele evento, o que me propiciou uma visão de como nossa produção em Ensino de Cenografia para professores de Teatro poderia se inserir naquele contexto tão polifônico e diverso.

Somente agora, em junho de 2019, as

\footnotetext{
$7 \mathrm{Na}$ Mostra dos Estudantes da PQ 2011 foram apresentados dois trabalhos: "Fando e Lis" - Direção e Cenografia de Felipe Cabral e André Luiz, e "ES3" - Direção e Cenografia de André Luiz, sob orientação Acadêmica da Profa. Dra. Naira Ciotti e do Prof. Dr. Sávio Araújo (DEART/UFRN).
}

contribuições que vimos desenvolvendo no campo das práticas de Ensino de Cenografia, nos últimos 10 anos, no CENOTEC/UFRN puderam ser compartilhadas com uma plateia internacional de profissionais, estudantes, professores e pesquisadores do campo da Cenografia $^{8}$, de modo a podermos avaliar os impactos desta produção junto a um público tão especial. Assim sendo, nos oito minutos que me foram destinados na PQ Talks, apresentei uma síntese das práticas mais significativas abrangendo o Ensino de Cenografia aplicado à formação de professores de Teatro e alguns desdobramentos destas práticas, realizados nas Escolas Públicas de Natal, RN, atendidas pelo ProgramaCAPES deBolsas de Iniciação à Docência - PIBID UFRN, Subprojeto TEATRO.

Figura 1 - Apresentação brasileira na PQ Talk sobre a contribuição da Academia para Cenografia PQ 2019, 11.06.2019.

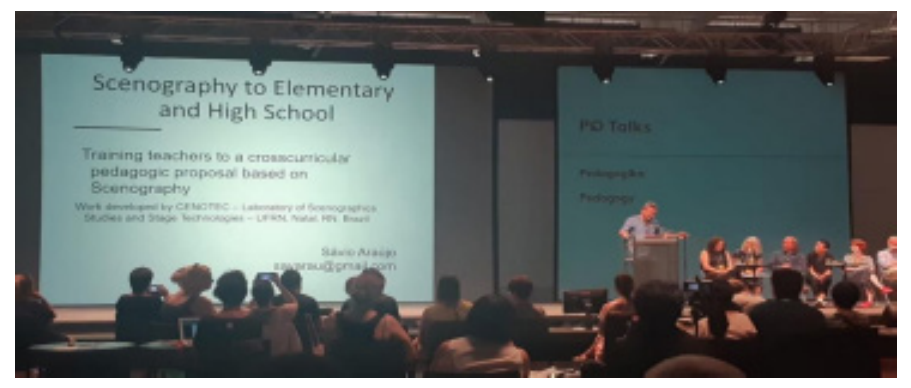

Fonte: Rosane Muniz.

O papel de um professor de Teatro na sociedade é muito importante, mas nem sempre bem compreendido. Um professor não é alguém que forma outras pessoas à sua imagem e semelhança, mas sim um profissional que ensina outras pessoas como elas podem dar o melhor de si, conhecendo e praticando uma determinada área de conhecimento. Alguns de nós se tornam artistas profissionais de teatro, outros se tornam espectadores. Ambos fundamentais para que o Teatro possa continuar existindo no mundo.

No trabalho que realizamos no Curso de Licenciatura em Teatro, por meio do CENOTEC Laboratório de Estudos Cenográficos e Tecnologias

\footnotetext{
8 Em 2014, pude apresentar o trabalho "Cenografia e Educação: práticas educativas no ensino fundamental em Natal, RN, Brasil", no encontro E-Scapes, em São Paulo, organizado por Aby Cohen e Rosane Muniz, pesquisadoras e membros da OISTAT - International Organization of Scenographers, Theatre Architects anda Technicians. Na ocasião as experiências sobre Ensino de Cenografia, produzidas pelo CENOTEC, puderam ser apresentadas para diversos membros da OISTAT, profissionais de diversos campos da Cenografia.
} 
da Cena, nós compartilhamos da mesma visão sobre Cenografia apresentada por Joslin McKinney e Philip Butterworth, em The Cambridge Introduction to Scenography, na qual: "Cenografia é a organização, manipulação e orquestração do espaço da cena" (MCKINNEY, BUTTERWORTH, 2009, p 04). Optamos por adotar essa perspectiva de uma Cenografia ampliada, articulando iluminação cênica, maquiagem, figurino, sonoplastia e cenários, sob uma mesma concepção de "Cenografia".

Numa perspectiva panorâmica de nossa área, percebo que em muitas reuniões e congressos de Cenografia, há sempre uma certa angústia em muitos de nós sobre como ampliar as fronteiras da Cenografia e despertar novas vocações e interesses entre os jovens, para que essa arte continue viva e pulsante.

Em nosso trabalho de formação de professores de teatro na UFRN, desenvolvemos estratégias didáticas e pedagógicas para ampliar o interesse dos estudantes pela Cenografia, e nos esforçamos para que esses futuros professores de Teatro sejam capazes de introduzír noções de Cenografia no Ensino Fundamental e Médio, favorecendo o potencial interdisciplinar da Cenografia e fomentando o interesse dos jovens por Teatro e Cenografia. Isso pode estimular o surgimento de vocações ou contribuir para a formação de espectadores.

No Brasil, temos cidades com um bom volume de produção teatral e equipamentos culturais, porém concentrada em determinadas regiões e muito precária em outras. Devido às dimensões continentais do Brasil e velhos problemas de gestão de políticas públicas na área de Arte e Cultura, muitas localidades não possuem sequer uma sala de teatro, ou edifício teatral, dificultando o acesso da população a essa arte. Desse modo, escolas e igrejas assumem, muitas vezes, também, o papel de equipamentos culturais, por onde muitos jovens travam seu primeiro contato com a Arte Teatral, o que aumenta as responsabilidades dos professores de Teatro. É sempre bom lembrar que não se pode esperar que um bom Cenógrafo seja um bom professor de Cenografia, mas devemos sempre esperar que um bom professor de Teatro seja capaz de desenvolver uma abordagem teatral que possa ir além das questões do ator, da direção e da dramaturgia.

Essa abordagem vem sendo desenvolvida na formação de professores no Curso de Licenciatura em Teatro da UFRN, Natal, RN, Brasil, desde 2007 e mais recentemente a partir de 2012, por meio do Programa de Bolsas de Iniciação à Docência - PIBID, na área de Teatro, o qual coordenei de agosto de 2012, quando de sua implantação, até fevereiro de 2018. Por meio dessa ação acadêmica de formação inicial e continuada de professores de teatro, vimos gradativamente uma mudança na programação pedagógica de currículos desenvolvidos por professores egressos desse programa, que passaram a abordar com maior frequência as questões de espaço na cena teatral e temas relacionados à cenografia e suas tecnologias.

A produção de um espaço para a cena é a episteme da CENOGRAFIA, é o modo pelo qual nossa área articula e produz conhecimentos. Por meio do conceito de Espaço/Tempo podemos dialogar com várias outras áreas do conhecimento que compõem os curriculos escolares.

O trabalho de criação cenográfica consiste em compreender as múltiplas interações entre os elementos de um mesmo sistema, no qual os diversos agentes cenográficos precisam manipular o espaço/tempo da ação cênica para operar transformações na vida das personagens por meio da maquiagem, do cenário, da movimentação de elementos de cena, da iluminação e das sonoridades.

\section{Figura 2 - Amplitude do trabalho coletivo realizado nas Artes Cênicas.}

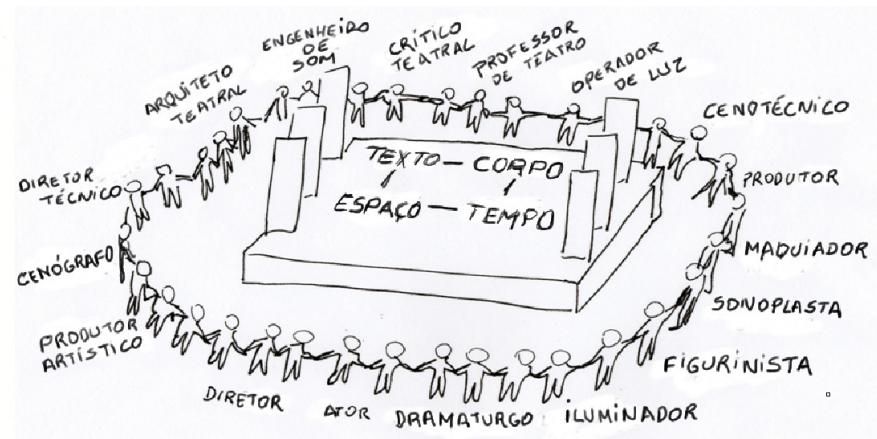

Fonte: Desenho do autor.

Em 2009, durante o período em que realizei meus estudos de Pós-Doutorado na University of British Columbia, em Vancouver, CA, compareci à USITT Anual Conference, em Cincinatti-OHIO, USA.

$\mathrm{Na}$ ocasião, perguntei a diferentes profissionais que atuam nos campos da Cenografia: quais conhecimentos científicos aprendidos no Ensino Fundamental e Médio ajudaram você a ser o profissional que você se tornou? 
Tabela 1 - Relações entre conhecimentos do Ensino Fundamental e Médio e conhecimentos em Cenografia.

\begin{tabular}{|l|l|l|}
\hline Matemática & $\begin{array}{l}\text { Proporções e escalas } \\
\text { Geometria } \\
\text { Cálculo } \\
\text { Sistemas métricos }\end{array}$ & $\begin{array}{l}\text { Cenários } \\
\text { Modelos e maquetes } \\
\text { Estruturas de palco } \\
\text { Figurino }\end{array}$ \\
\hline Física & $\begin{array}{l}\text { Óptica } \\
\text { Eletricidade } \\
\text { Magnetismo } \\
\text { Luz e Cor } \\
\text { Som e Acústica } \\
\text { Mecânica e Dinâmica }\end{array}$ & $\begin{array}{l}\text { Iluminação Cênica } \\
\text { Refletores e equipamen- } \\
\text { tos } \\
\text { Luz como Lica } \\
\text { Songlia, Voz e } \\
\text { Maquinário de Palco }\end{array}$ \\
\hline Ciências Biológicas & $\begin{array}{l}\text { Psicologia } \\
\text { Biomecânica }\end{array}$ & $\begin{array}{l}\text { Corpo e Performance } \\
\text { Pré-expressividade }\end{array}$ \\
\hline Química & $\begin{array}{l}\text { Funções Orgânicas } \\
\text { Estruturas e Ligações } \\
\text { Química Aplicada }\end{array}$ & $\begin{array}{l}\text { Maquiagem } \\
\text { Tintas } \\
\text { Materiais para Cenário }, \\
\text { Figurino e Iluminação }\end{array}$ \\
\hline
\end{tabular}

As diferentes respostas que obtive, me ajudaram a montar o quadro acima, contendo diversos pontos de intersecção entre aspectos do trabalho cenográfico e conteúdos de diferentes áreas de conhecimento, demonstrando a riqueza multidisplinar inerente à Cenografia, e ressaltando o potencial contido no Ensino de Cenografia.

Assim, de volta ao Brasil, em 2012, pude coordenar um Subprojeto no Programa PIBID/ CAPES, que oferecia bolsas de iniciação à docência para estudantes das Licenciaturas, no nosso caso em Teatro. Quatro escolas públicas da cidade de Natal - RN puderam ser atendidas e nelas desenvolvemos algumas experiências significativas na introdução de Cenografia nas atividades de Ensino de Teatro que compõem a organização curricular do Ensino Fundamental e Médio.

Participaram desta experiência as seguintes escolas da rede pública do município de Natal e da rede estadual do RN: Ensino Fundamental (Escola Municipal Professor Laércio Monteiro Fernandes I Vale Dourado), (Escola Municipal José Frazão ( Vale Dourado), Escola Estadual Lauro de Castro / Cidade da Esperança); Ensino Médio (Escola Estadual Prof. Veríssimo de Melo / Felipe Camarão).
Figuras 3 e 4 - Aula de iluminação para crianças do Ensino Fundamental.

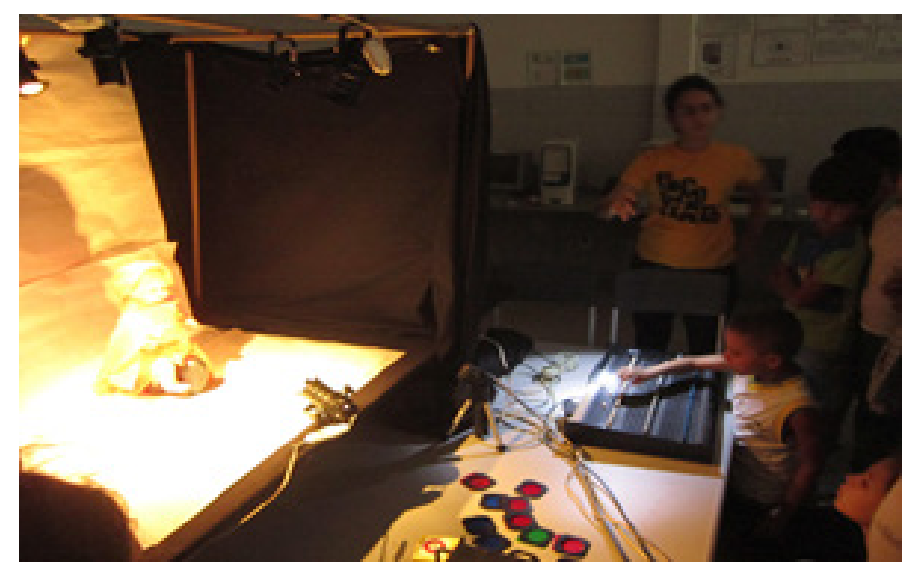

Fonte: Fotos do autor.

As figuras 3 e 4, mostram uma aula de iluminacão cênica, na Escola Municipal Laércio Fernandes, uma escola pública da periferia de Natal. Para simular a ideia de um palco, construimos uma caixa preta com materiais alternativos e baratos, com uma estrutura feita de canos plásticos, revestida com pano preto de baixo custo. Os refletores são do tipo micro par, que custam em média 10 dólares no mercado local, e podem ser utilizadas tanto com lâmpadas de LED amarelas ou com lâmpadas incandescentes. O console para controle da iluminação do sistema usado nessa aula foi um modelo analógico antigo. Este tipo de mesa de iluminação já está fora de uso na maioria dos Teatros contemporâneos, porém, ainda pode ser um equipamento eficiente aplicado para fins didáticos. O objetivo da atividade aqui apresentada foi demonstrar para as crianças da $3^{a}$ série, na faixa entre 8 e 9 anos, como a posição, intensidade e cor da luz pode alterar a percepção visual do objeto iluminado. Nesse acaso o objeto em questão foi escolhido entre os brinquedos da escola.

Nossa intenção não é ensinar a linguagem da iluminação cênica para esses estudantes, mas sim, promover um tipo de educação estética, que leve-os a pensar nas diversas situações cotidianas, nas quais a luz é usada para modificar a aparência das coisas e a percepção visual que temos delas. Como acontece em vitrines de lojas, supermercados, e lojas de departamentos, entre outras situações relacionadas a hábitos de consumo nas sociedades contemporâneas.

Como tarefa de casa, o professor propõe que os estudantes investiguem possibilidades de exercícios de iluminação de objetos do cotidiano das crianças, como brinquedos e outros objetos, usando fontes luminosas como lanternas, velas e outros 
dispositvos luminosos. NaFigura 5, vemos uma criança experimentando iluminar sua boneca, alterando a cor da luz com papel celofane e uma lanterna.

Figura 5 - Objeto de aprendizagem - Criança fazendo tarefa de casa sobre iluminação.

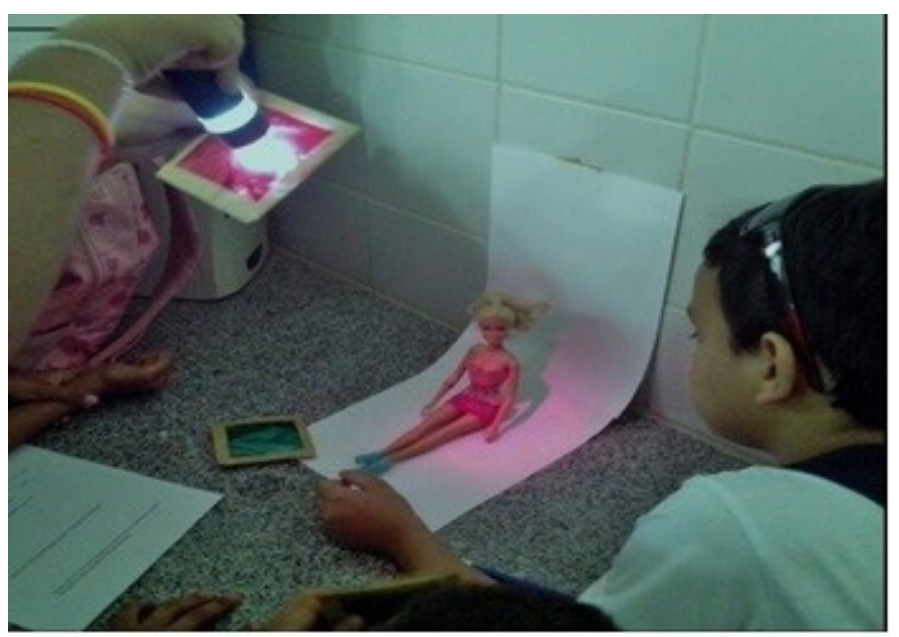

Fonte: Foto do autor.

Essetipo deatividadenosfaz refletir sobrecomo o nosso interesse por um objeto pode ser influenciado pela percepção produzida por meio da iluminação.

Ainda no Ensino Fundamental, o PIBID TEATRO trabalhou com a obra literária "Sitio do Pica Pau Amarelo", de Monteiro Lobato.

Figura 6 - Exercício de desenho de caracterização de personagem - maio/2013.

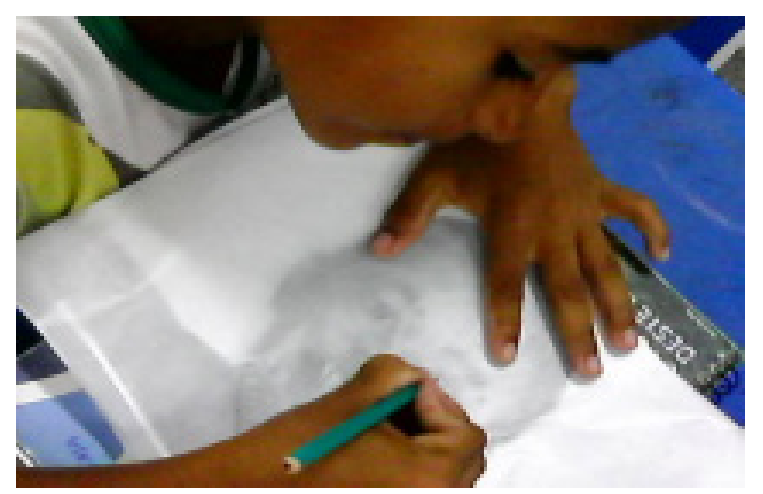

Fonte: Ildisnei Medeiros.

Na figura 6, vemos uma criança utilizando uma técnica demonstrada por Richard Corson e James Glavan (2001), no livro Stage Make Up, uma importante referência no ensino de maquiagem artística nos Estados Unidos, na qual uma pessoa pode produzir alterações na própria fisionomia, por meio do desenho, transformando suas feições nas feições atribuídas ao personagem. Neste exercício, as crianças criaram intervenções em sua aparência desenhando num papel semitransparente sobre a própria fotografia para que fiquem com a aparência dos personagens da obra estudada. Essa atividade aborda o conceito de "Caracterização", que consiste em dar forma física a um personagem de uma obra literária ou dramatúrgica. Como resultado dessa atividade os estudantes criaram "cosplays" de seus personagens favoritos, construindo seus próprios designs de figurino e maquiagem.

No âmbito do Ensino Médio, uma atividade que experimentamos com sucesso foi a desmontagem de um espetáculo teatral revelando como funciona a tecnologia de cena utilizada na produção de efeitos teatrais. Uma espécie de making of ao vivo, realizado imediatamente após a apresentação de um espetáculo de curta duração. Analisamos aspectos como a ficha técnica do espetáculo, planta baixa do cenário, os dispositvos de iluminação e som, bem como os materiais usados na confecção de figurinos e adereços. Nas fotos a seguir, vemos essa atividade sendo realizada para uma plateia de 150 estudantes do Instituto Federal de Educação Tecnológica do Rio Grande do Norte, IFRN. Nessa discussão, também abordamos o quadro apresentado na Tabela 1, no qual relacionamos as tecnologias da cena e os conteúdos de diferentes matérias do Ensino Médio, para provocar estudantes e professores a refletirem sobre o potencial concentrado nos estudos cenográficos e as relações com outras disciplinas do currículo no Ensino Médio.

Nesta atividade, pudemos discutir diversos aspectos envolvidos nas tecnologias do espetáculo em discussão, mostrando como as tecnologias de cena dialogam com conteúdos como óptica, magnetismo, dinâmica, relações matemáticas de proporcionalidade (escalas), propriedades acústicas dos materiais, entre outros.

$\mathrm{Na}$ ocasião, pudemos contar com a valiosa contribuição do Prof. Zanoni Tadeu (IFRN), da área de Física, que comentou as relações entre as tenologias apresentadas e o Ensino de Física. 
Figuras 7 e 8 - Aula espetáculo de Tecnologia Cênica IFRN, Natal, 2013.
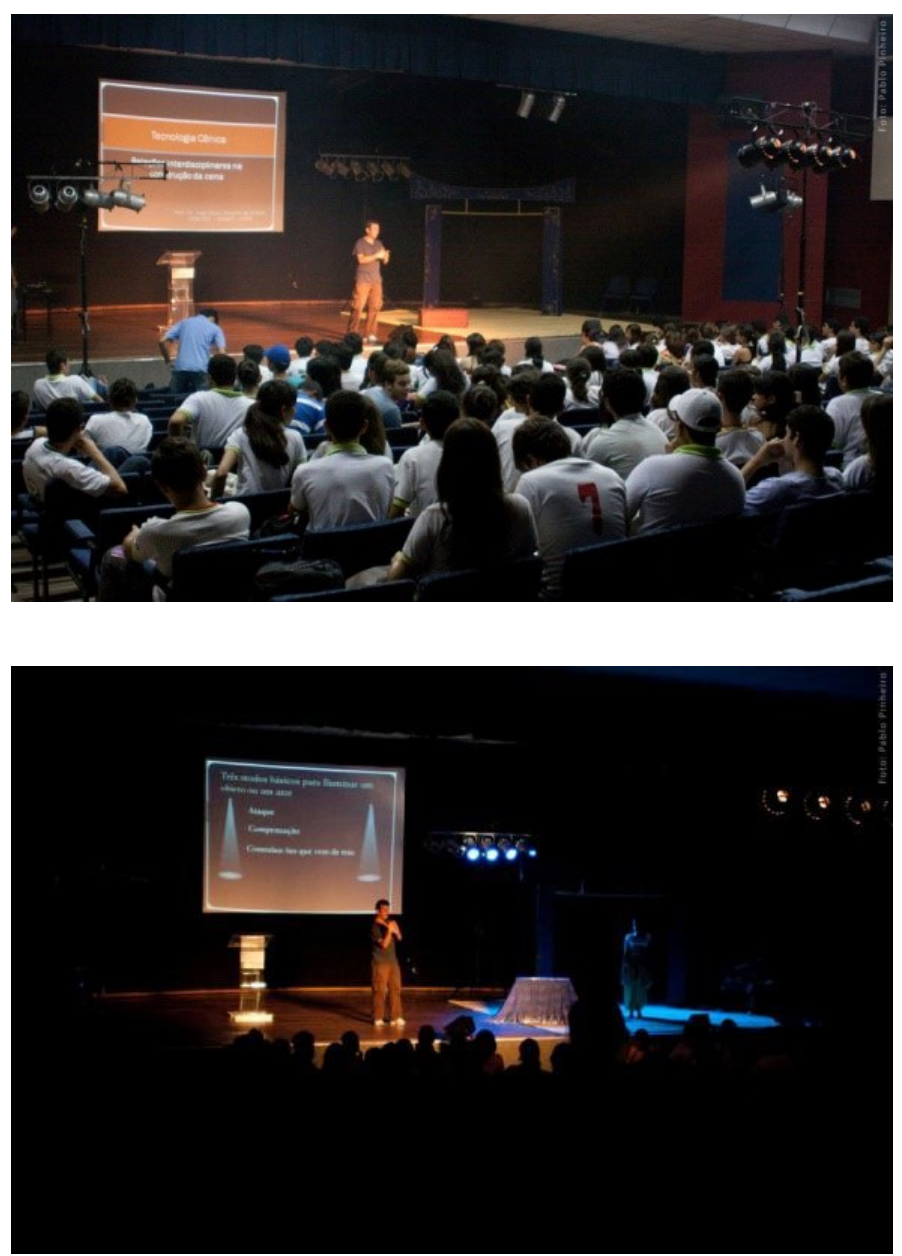

Fonte: Fotos de Pablo Pinheiro.

Outra estratégia didático pedagógica desenvolvida no CENOTEC para ensino de Cenografia, nos foi inspirada por Pamela Howard (2002), em seu livro What is Scenography? Nessa obra, Howard cita uma cartografia que fez da peça O Jardim das Cerejeiras, de Tcheckov, narrando como a cartografia a ajudava a compreender a organização espacial contida na narrativa da peça.

Tomamos emprestada essa ideia e pedimos aos estudantes do Curso de Licnenciatura em Teatro da UFRN, no componente curricular CENOTEC I: Introdução à Cenografia, que escrevessem minibiografias, uma breve história da vida de cada um, de quando nasceram até entrarem na universidade. abordando somente aspectos "publicizáveis"9 de suas histórias de vida.

Em seguida, os estudantes produziram cartografias como meio para experimentar organizações do espaço dessas narrativas sobre um único suporte: desenhos numa folha de papel, colagens sobre cartolina, entre outros.

Desse modo, os estudantes entram em contato com o principal desafio epistêmico da atividade cenográfica:transporumanarrativapara oespaçocênico,

$\mathrm{Na}$ figura 9 , vemos a realização de uma performance construída a partir de uma cartografia de percurso de vida (Figura 10), construída por meio dessa abordagem pedagógica.

Figura 9 - Performance Eu camaleoa, criada à partir de cartografia de percurso de vida, (CENOTEC/UFRN, Maio, 2014).

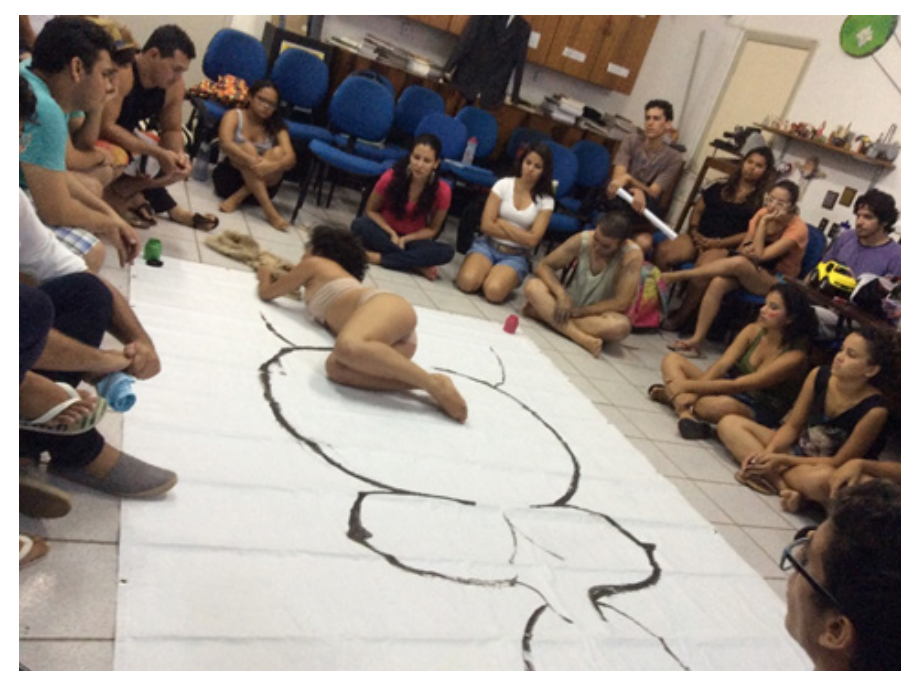

Fonte: Foto do autor.

9 Esse cuidade se faz necessário em função de que muitos aspectos da vida dos estudantes contêm forte carga emocional e afetiva. Uma apresentação descuidada dessas minibiografias pode expor desnecessariamente os estudantes e banalizar suas experiências de vida. Além disso, nosso foco está no modo como organizam essas narrativas de vida e não no seu potencial psicodramático. 
Figura 10 - Cartografia de percurso de vida (CENOTEC/UFRN, Maio, 2014).

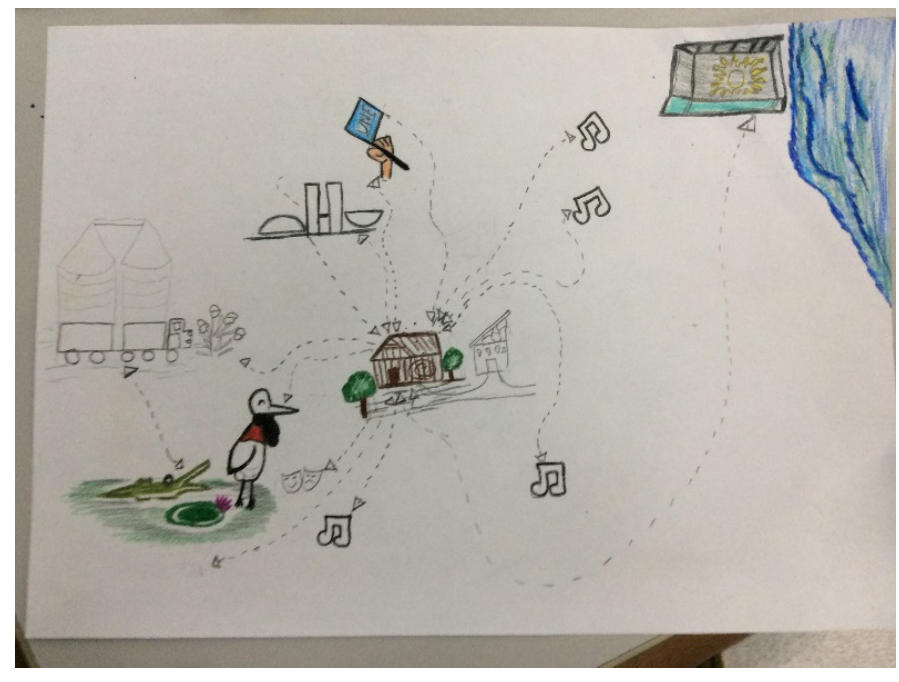

Fonte: Foto do autor.

No curso de Licenciatura em Teatro da UFRN, não formamos profissionais de Cenografia, mas sim, desenvolvemos experiências de produção de conhecimento cenográfico com Licenciandos em Teatro, futuros professores, capacitando-os para abordar a Cenografia, suas epistemes, técnicas e tecnologias, em programações pedagógicas para sala de aula, nas escolas do Ensino Fundamental e Médio.

Esse trabalho gerou 05 monografias de conclusão de curso $^{10}, 03$ dissertações de mestrado ${ }^{11}$,

10 SILVA, Ildisnei Medeiros da. Ensino de Teatro e Educação dialógica: uma experiência de organização pedagógica no PIBI$D$-Teatro/UFRN. Trabalho de Conclusão de Curso. Licenciatura em Teatro/UFRN, 2015; MEDEIROS, Suame. Ensino de Teatro e Iluminação Cênica: experiências no PIBIDTeatro/UFRN. Trabalho de Conclusão de Curso. Licenciatura em Teatro/UFRN, 2015; SILVA, Stephanie Cristina de Carvalho, Do ateliê ao palco: a construção da personagem Cosplay. Trabalho de Conclusão de Curso. Licenciatura em Teatro/UFRN, 2015; DANTAS, Matheus Giannini Caldas, Artista-Professor-Pesquisador: Relatos de uma Experiência Formativa no PIBID Teatro UFRN. Trabalho de Conclusão de Curso. Licenciatura em Teatro/UFRN, 2016; ALVES, Rafael, A Importância da Música na Formação do Professor de Teatro. TrabaIho de Conclusão de Curso. Licenciatura em Teatro/UFRN, 2019.

11 SILVA, Ildisnei Medeiros da. Ensino de Teatro e Diálogo Freireano: Uma experiência junto ao PIBID-Teatro/UFRN. Dissertação de Mestrado. Programa de Pós Graduação em Artes Cênicas - PPGArC/UFRN. 2015; SILVA, Joseane Maria da. A Maquiagem como Experiência Artística e Pedagógica. Dissertação de Mestrado. Programa de Pós Graduação em Artes Cênicas - PPGArC/UFRN, 2019 (qualificada e em fase de preparação para defesa); ARAÚJO, Priscila Cristiane Lopes de. O Jogo Didático no Ensino de Iluminação Cênica. (título provisório, dissertação em desenvolvimento). Programa de Pós Graduação em Artes Cênicas - PPGArC/UFRN, 2019. uma tese de Doutorado, entre outros artigos e trabalhos apresentados em Congressos da área.

Desse modo, esperamos que os professores que formamos desenvolvam práticas de Ensino de Teatro abragentes e inclusivas, que propiciem uma visão acerca das Artes Perfomáticas para além do que se vê no palco, explorando os diferentes saberes e especialidades presentes nessa área e fortalecendo o papel da Cenografia na formação de plateias e futuros profissionais do ramo.

Destacamos ainda que todo trabalho de investigação pedagógica para o Ensino de Cenografia que realizamos está referenciado no pensamento do educador brasileiro Paulo Freire $(1981,2000)$ e suas concepções acerca de Educação Dialógica, bem como nas reflexões produzidas para o Ensino de Ciências, por José André Angotti, Demétrio Delizoicov e Marta Pernambuco (2002), que organizaram uma síntese didática e pedagógica para uma Pedagogia Dialógica, na qual os processos de ensino são encarados como processos de construção de conhecimento, mediados por um estudo da realidade de educandos e educadores e organizados em momentos pedagógicos que norteiam o processo de educação dialógica.

Referências

ANGOTTI, José André; DELIZOICOV, Demetrio; PERNAMBUCO, Marta Maria. Ensino de Ciências: fundamentos e métodos. São Paulo. Ed. Cortez. 2002.

ARAÚJO, José Sávio Oliveira de. A Cena Ensina: uma proposta pedagógica para formação de professores de teatro. Tese (Doutorado). Natal. Programa de Pós-Graduação em Educação. Universidade Federal do Rio Grande do Norte. 2005. $177 f$.

BACHELARD, Gaston. Epistemologia: trechos escolhidos, Dominique Lecourt (org). Rio de Janeiro: Zahar Editores, 1983.

CORSON, Richard; GLAVAN, James. Stage Make Up. Pearson Custom Publishing, 2001.

FREIRE, Paulo. Pedagogia do oprimido. 10 ed. Rio de Janeiro: Paz e Terra, 1981.

FREIRE, Paulo. Pedagogia da Autonomia: saberes necessários à prática educativa. $15 \mathrm{ed}$. Rio de Janeiro: Paz e Terra, 2000. 
HOWARD, Pamela. What is Scenography? Abingdon: Routledge. 2002.

MCKINNEY, Joslin; BUTTERWORTH, Philip. The Cambridge Introduction to Scenography. Cambridge: The Cambridge University Press, 2009.

MCKINNEY, Joslin. Invitation Letter, sent to the invited panellists, by e-mail. 15 fev. 2019

PRAGUE QUADRENNIAL. Press release. 09 mai. 2019. Disponível em: < http://www.pq.cz/press/ >. Acesso em: 09 mai. 2019.

Recebido: 02/10/2019 Aprovado: 25/03/2020 